\title{
Let-7a inhibits growth and migration of breast cancer cells by targeting HMGA1
}

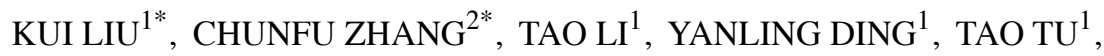 \\ FANGFANG ZHOU ${ }^{1}$, WENKAI QI ${ }^{1}$, HUABIAO CHEN ${ }^{1,3}$ and XIAOCHUN SUN ${ }^{1}$
}

\author{
${ }^{1}$ School of Medicine, Jiangsu University, Jiangsu Key Laboratory of Clinical Laboratory Medicine, Zhenjiang, \\ Jiangsu 212013; ${ }^{2}$ The Second People's Hospital of Kunshan, Kunshan, Jiangsu 215300, P.R. China; ${ }^{3}$ Vaccine and \\ Immunotherapy Center, Massachusetts General Hospital and Harvard Medical School, Boston, MA 02114, USA
}

Received January 25, 2015; Accepted March 5, 2015

DOI: 10.3892/ijo.2015.2949

\begin{abstract}
Let-7 is one of the earliest discovered microRNAs (miRNAs) and has been reported to regulate self renewal and tumorigenicity of breast cancer cells. Let-7a is a member of this family and its function has not been fully characterized in breast cancer. First, total RNAs of breast cancer cells (MDAMB-231, MCF-7), breast cancer tissues and corresponding adjacent normal tissues were extracted and used to detect let-7a expression by qRT-PCR. Secondly, the effects of let-7a on proliferation, colony formation, migration and invasion of breast cancer cells were assessed by in vitro cell culture experiments. Finally, western blotting was performed to demonstrate how let-7a regulated HMGA1 expression. We found that let-7a expression was significantly lower in breast cancer cells and breast cancer tissues compared to corresponding adjacent normal tissues. Cell proliferation, colony formation, migration and invasion were decreased after overexpression of let-7a in breast cancer cells and vice versa. Furthermore, we identified the high mobility group A1 (HMGA1) as a potential target gene of let-7a. Protein expression of the target gene was significantly downregulated in let-7a mimic transfected breast cancer cells and significantly upregulated in let-7a inhibitor transfected breast cancer cells. Our data suggest that let-7a plays an important role as a tumor suppressor gene by targeting HMGA1, which may open novel perspectives for clinical treatments against breast cancer.
\end{abstract}

Correspondence to: Dr Xiaochun Sun, School of Medicine, Jiangsu University, Jiangsu Key Laboratory of Clinical Laboratory Medicine, Zhenjiang, Jiangsu 212013, P.R. China

E-mail: xiaochun@ujs.edu.cn

Professor Huabiao Chen, Vaccine and Immunotherapy Center, Massachusetts General Hospital and Harvard Medical School, Boston, MA 02114, USA

E-mail: huabiao.chen@mgh.harvard.edu

*Contributed equally

Key words: breast cancer, miRNA, let-7a, HMGA1

\section{Introduction}

Breast cancer is the most commonly diagnosed cancer in women, and the second leading cause of cancer deaths in the developed world. Although many advanced treatments have emerged following improvement in clinical instruments and methods, metastasis still leads to cancer mortality and poor prognosis (1). Almost $30 \%$ of early breast cancers eventually develop recurrence and metastasis (2). As a result, research and development of treatment targeting breast cancer are of great importance.

miRNAs are endogenous, noncoding small RNAs with 20-25 nucleotides in length (3). They play an important regulatory role through complimentary binding of the 3 ' untranslated regions (UTRs) of target genes thus resulting in the degradation of the target mRNA and inhibition of translation (4). Since the initial discovery of miRNAs in 1993 (5), they have been shown to affect multiple cellular processes (6), and in particular, have been shown to play significant roles in cancer development and progression $(7,8)$. Abnormal patterns of miRNA expression have been observed in various cancer types, including breast cancers $(6,9-11)$, colon (12), lymphomas and leukemias (13), head and neck (14) and hepatocellular carcinoma (15). Functionally, abnormal miRNA expression can affect tumor cell proliferation (16), apoptosis (8), development of metastases (17), invasion $(16,17)$, chemo- and radiationsensitivity (18). Previous studies have indicated that miRNAs can be useful for cancer diagnosis and therapy (19). Let-7 was the first identified miRNA and its downregulation has a prognostic impact on the survival of surgically treated lung cancer patients (20). Let-7a expression increases after differentiation and in mature tissue, but is nearly undetectable in the embryonic stage (21). Although let-7 family members can all function as tumor suppressors (22-24), let-7a is the one that is the most reported to downregulate c-myc (24-26).

In this study, we investigated function of let-7a in human breast cancer. First, total RNAs of breast cancer cells (MDAMB-231, MCF-7), breast cancer tissues and corresponding adjacent normal tissues were extracted and used to detect let-7a expression by qRT-PCR. Secondly, the effects of let-7a on proliferation, colony formation, migration and invasion of breast cancer cells were assessed by in vitro cell culture 
experiments, which further clarified the role of let-7a in breast cancer development. Finally, western blotting demonstrated that let-7a negatively regulated HMGA1 protein expression which in turn contributed to tumor formation.

\section{Materials and methods}

Breast cancer tissues and normal tissues. Documented informed consent was obtained from all subjects and the Ethics Committee of Jiangsu University approved all aspects of the study. Breast cancer tissues and corresponding adjacent normal tissues were obtained at the Department of Surgery, the Second People's Hospital of Kunshan, China. Both tumor tissues and corresponding adjacent normal tissues were histologically confirmed. The tissues obtained were immediately stored at $-80^{\circ} \mathrm{C}$.

Cell culture. The human breast cancer cell lines MCF-7, and MDA-MB-231 were provided from Nanjing University and cultured in Dulbecco's modified Eagle's medium with low glucose (L-DMEM, Gibco) supplemented with $10 \%$ fetal bovine serum (FBS, ExCell Biology, China) at $37^{\circ} \mathrm{C}$ in humidified $5 \% \mathrm{CO}_{2}$.

miRNA transfection. Let-7a mimics or mimics negative control (mimics NC) and let-7a inhibitor or inhibitor negative control (inhibitor NC) were synthesized and purified by GenePharma (Shanghai, China). All of the sequences are listed in Table I. Transfection was performed with lipofectamine 2000 (Invitrogen). Let-7a mimics and let-7a inhibitors were used at a concentration of $100 \mathrm{nM}$. The same concentrations of mimics and inhibitor negative controls were used.

$R N A$ isolation and $q R T-P C R$. The total RNA of tissues was isolated with the TRIzol reagent (Invitrogen) according to the manufacturer's instructions. The RNA was also isolated with the TRIzol reagent from cell lines which were transfected with let-7a mimic and negative control or let-7a inhibitor and inhibitor negative control for $24 \mathrm{~h}$. For measurement of let-7a RNA expression, qRT-PCR was performed using a SYBR green-containing PCR kit (GenePharma). For the detection of HMGA1 mRNA, cDNA was synthesized from $1 \mu \mathrm{g}$ of total RNA using the reverse reaction kit in accordance with the manufacturer's instructions (Thermo). After that, qRT-PCR was performed using UltraSYBR Mixture (with ROX) Assay kits (CWBio, China) according to the manufacturer's instructions. The CFX-96 real-time fluorescence thermal cycler (Bio-Rad) was used for quantitative miRNA and mRNA detection. The relative expression levels of miRNA and mRNA were normalized to the expression of U6 snRNA and $\beta$-actin mRNA, respectively. The expression of each gene was quantified by measuring cycle threshold $(\mathrm{Ct})$ values and normalized using the $2^{-\Delta \mathrm{Ct}}$ or $2^{-\Delta \Delta \mathrm{Ct}} \mathrm{Ct}$ method relative to U6 snRNA or $\beta$-actin mRNA. All the primer sequences are listed in Table II.

Cell proliferation assay. Cell proliferation was measured 3 days after transfection with let-7a mimic and negative control or let-7a inhibitor and inhibitor negative control by Thiazolyl Blue Tetrazolium Bromide (MTT, Amresco). The results are represented as proliferating cells quantified at OD
Table I. The sequence of let-7a mimics, let-7a inhibitor and negative control.

Name Sequence

Hsa-let-7a mimic

Sense

5'-UGAGGUAGUAGGUUGUAUAGUU-3'

Anti-sense 5'-CUAUACAACCUACUACCUCAUU-3'

Mimic-negative control

Sense

Anti-sense

5'-UUCUCCGAACGUGUCACGUTT-3'

5'-ACGUGACACGUUCGGAGAATT-3'

Hsa-let-7a inhibitor

5'-AACUAUACAACCUACUACCUCA-3'

Inhibitor negative control 5'-CAGUACUUUUGUGUAGUACAA-3'

Table II. Specific primers for target and control genes.

\begin{tabular}{ll}
\hline Name & \multicolumn{1}{c}{ Sequence } \\
\hline Let-7a primer & F: 5'-CGATTCAGTGAGGTAGTAGGTTGT-3' \\
& R: 5'-TATGGTTGTTCTGCTCTCTGTCTC-3' \\
U6snRNA primer & F: 5'-ATTGGAACGATACAGAGAAGATT-3' \\
& R: 5'-GGAACGCTTCACGAATTTG-3' \\
HMGA1 primer & F: 5'-CAGCGAAGTGCCAACACCTA-3' \\
& R: 5'-AGGAAGCTGCTCCTCCAGTG-3' \\
3-actin primer & F: 5'-TGGCACCCAGCACAATGAA-3' \\
& R: 5'-CTAAGTCATAGTCCGCCTAGAAGCA-3'
\end{tabular}

F, forward; R, reverse.

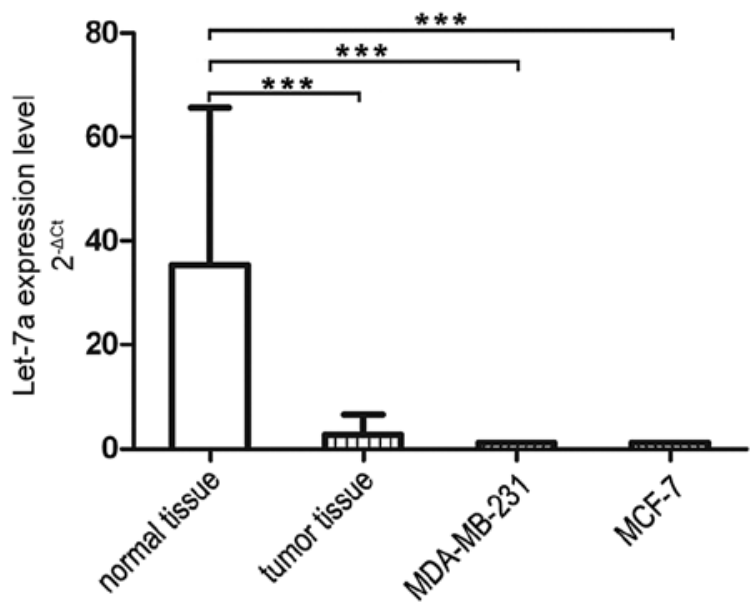

Figure 1. Let-7a levels in breast cancer tissues and breast cancer cell lines. The RNA expression of let-7a was analyzed by qRT-PCR. The expression level of let-7a is significantly decreased in the breast cancer tissues and breast cell lines (MDA-MB-231, MCF-7) compared to the adjacent normal tissues. The graph represents the mean of $2^{-\Delta \mathrm{Ct}}$ values $\pm \mathrm{SEM}\left({ }^{* * *} \mathrm{P}<0.001\right)$. SEM, standard error of the mean.

490 nm by FLx800 Fluorescence Microplate Reader (BioTek). The experiment was performed in triplicate. 

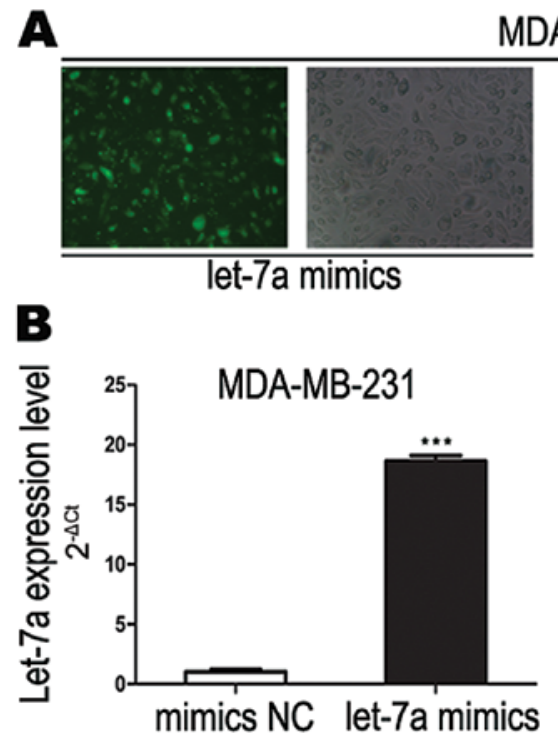

MDA-MB-231

D $\quad$ MCF-7

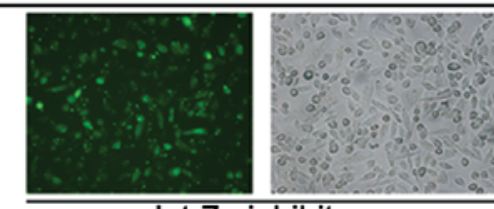

let-7a inhibitor

C

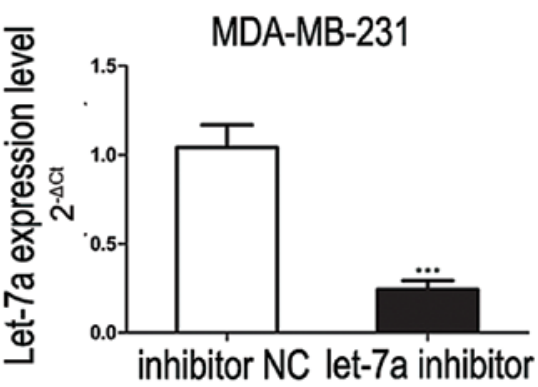

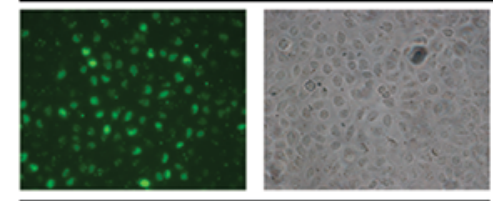

let-7a mimics

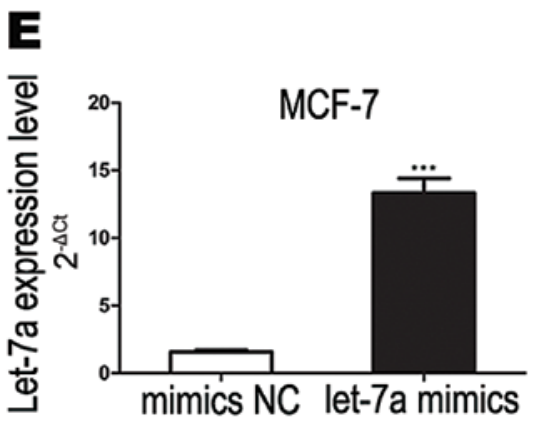

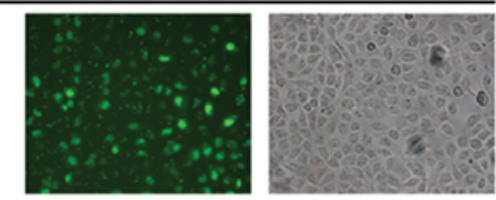

let-7a inhibitor

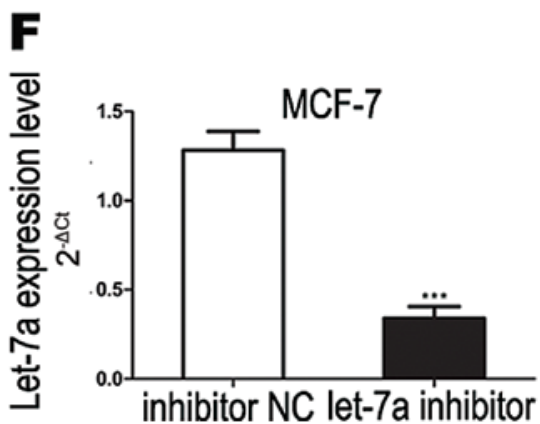

Figure 2. The breast cancer cells were transiently transfected with let-7a mimics and let-7a inhibitor. Transfection efficiency of the breast cell lines (MDAMB-231, MCF-7) was estimated by fluorescence microscopy $6 \mathrm{~h}$ (x200) after transfection of let-7a mimics and let-7a inhibitor, respectively, presented as FAM-expressing cells (A and D, left panel) and differential interference contrast images (A and D, right panel). qRT-PCR was used to investigate let-7a transfection efficiency. Let-7a was significantly increased or decreased in response to let-7a mimics or let-7a inhibitor compared to their negative controls (mimics NC or inhibitor NC) (B, C, E and F). The graph represents the mean of $2^{-\Delta C t}$ values \pm SEM $(* * * 00.001)$. SEM, standard error of the mean.

Colony forming assay. The tumor cells were transfected with let-7a mimic and negative control or let-7a inhibitor and inhibitor negative control for $6 \mathrm{~h}$. Then, $1 \times 10^{3}$ cells were seeded into 6-well plates and incubated for 10 days, fixed and stained, followed by colony counting. The experiment was performed in triplicate.

Wound healing assay. The tumor cells were seeded into 6-well plates and transfected with let-7a mimic and negative control or let-7a inhibitor and inhibitor negative control and allowed to grow until $100 \%$ confluency. Next, the cell layer was scratched through the central axis using a sterile plastic tip and loose cells were washed away by PBS. The wound healing was observed and photographed at three pre-selected time points $(0,24$, and $48 \mathrm{~h}$ ) in three randomly selected microscopic fields for each condition and time point. The experiment was performed in triplicate.
Cell invasion assay. The tumor cell invasion was evaluated using a Transwell insert ( $8 \mu \mathrm{m}$, Corning). Cells were transfected with let-7a mimic and negative control or let-7a inhibitor and inhibitor negative control. After $24 \mathrm{~h}$, the cells were starved in L-DMEM without fetal bovine serum overnight, and then $4 \times 10^{4}$ cells resuspended in $0.2 \mathrm{ml}$ serum-free L-DMEM were added to the upper chamber and L-DMEM containing $10 \%$ fetal bovine serum was added to the lower chamber as a chemoattractant at $37^{\circ} \mathrm{C}$ in humidified $5 \% \mathrm{CO}_{2}$ for $14 \mathrm{~h}$ (MDA$\mathrm{MB}-231)$ or $16 \mathrm{~h}$ (MCF-7). The invasive cells were fixed and stained with $0.1 \%$ crystal violet. Three low-magnification areas (x100) were randomly selected and counted for the cell numbers. The experiment was performed in triplicate.

Protein extraction and western blot analysis. Cells were transfected with let-7a mimic and negative control or let-7a inhibitor and inhibitor negative control. After $48 \mathrm{~h}$, the total 

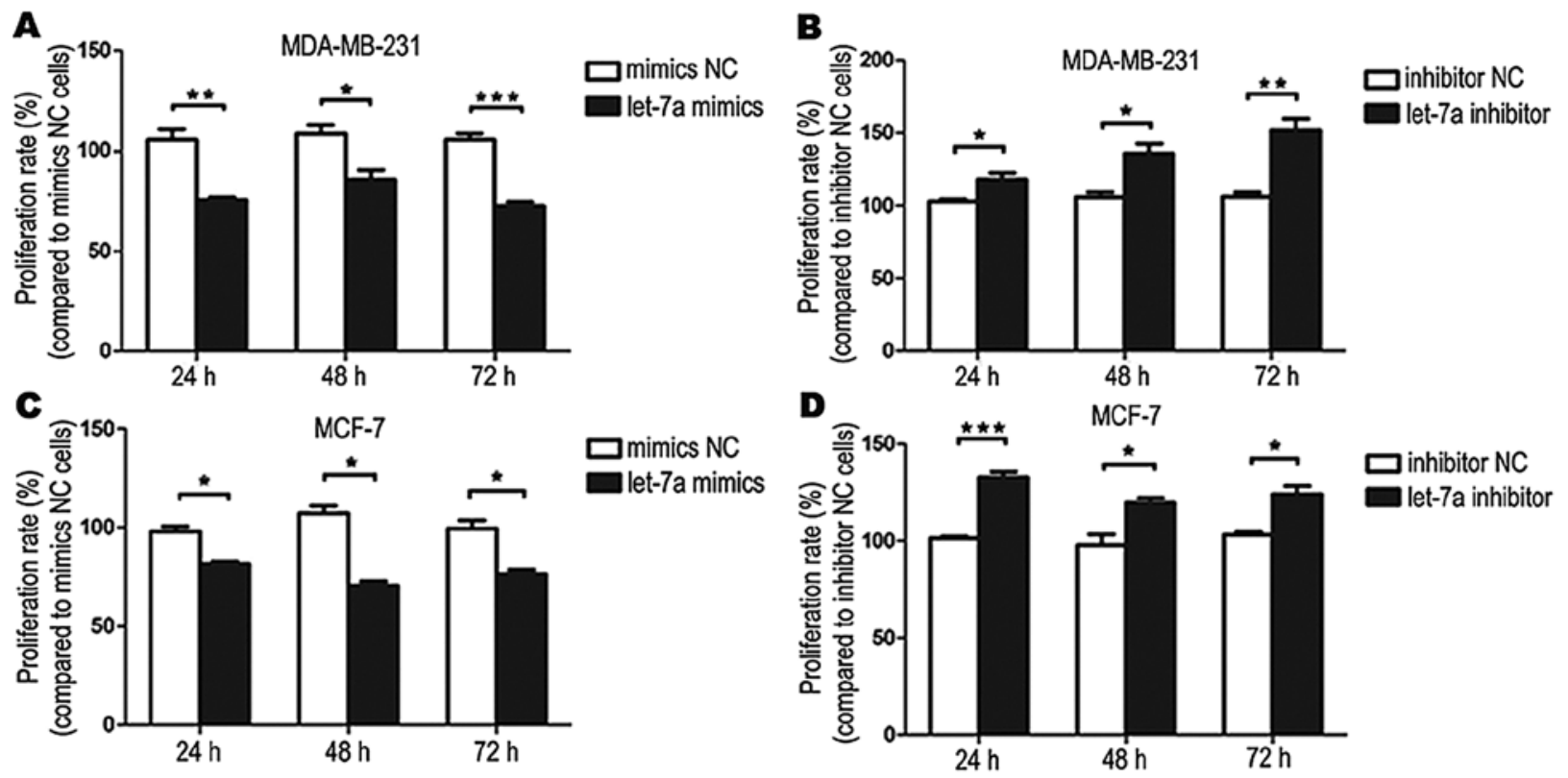

Figure 3. Let-7a inhibited cell proliferation. The proliferation of breast cancer cells lines (MDA-MB-231, MCF-7) transfected with let-7a mimics or let-7a inhibitor were examined at various time points $(24,48$ and $72 \mathrm{~h})$ by MTT assays. The graph represents relative proliferation rate of cells transfected with let-7a mimics (A and C) or let-7a inhibitor (B and D) compared to their negative controls (mimics NC or inhibitor NC) shown as mean $\pm \mathrm{SEM}\left({ }^{*} \mathrm{P}<0.05,{ }^{* *} \mathrm{P}<0.01\right.$, $\left.{ }^{* * *} \mathrm{P}<0.001\right)$. SEM, standard error of the mean.

A

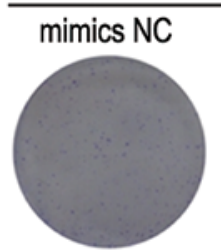

inhibitor NC
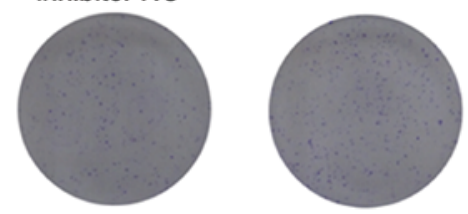

MDA-MB-231

B

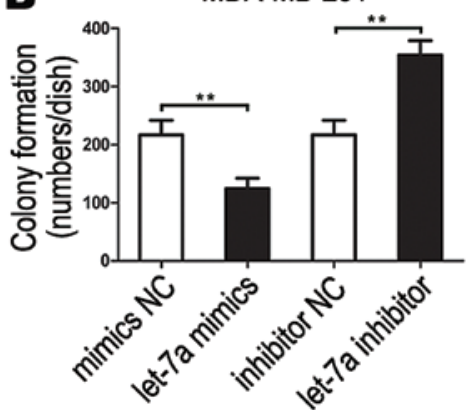

MCF-7

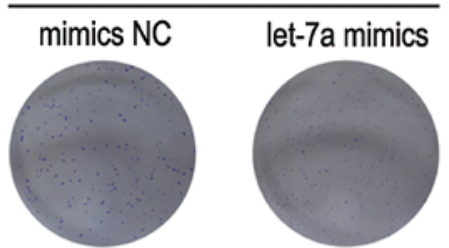

inhibitor NC

let-7a inhibitor
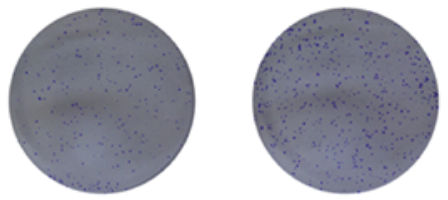

MCF-7

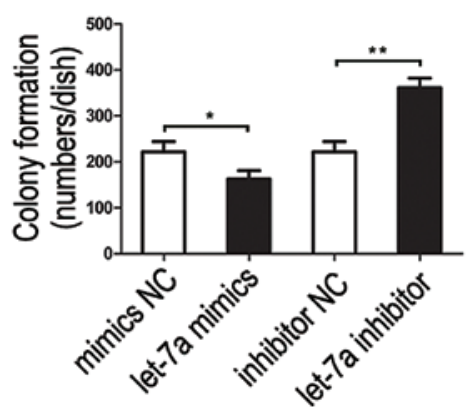

Figure 4. Let-7a inhibited cell colony formation. The colonies of breast cancer cells lines (MDA-MB-231, MCF-7) transfected with let-7a mimics or let-7a inhibitor were stained by crystal violet at day 10 post-transfection and compared to their negative controls (mimics NC or inhibitor NC) (A). The graph represents the mean of colony number $\pm \mathrm{SEM}\left({ }^{*} \mathrm{P}<0.05,{ }^{* *} \mathrm{P}<0.01\right)$. SEM, standard error of the mean $(\mathrm{B})$.

cellular protein of the cells was extracted using a modified radioimmunoprecipitation assay (RIPA, Vazyme Biotech, China) lysis buffer and phenylmethanesulfonyl fluoride (PMSF, Beyotime, China). The protein concentration was then determined by NanoDrop 1000 spectrophotometer
(Thermo) and equal amounts of protein lysates $(100 \mu \mathrm{g})$ were separated by $12 \%$ sodium dodecyl sulfate polyacrylamide gel electrophoresis (SDS-PAGE, Beyotime) and then transferred to polyvinylidene fluoride (PVDF) membrane (Beyotime). The membranes were blocked with $5 \%$ defatted milk/TBST 
A
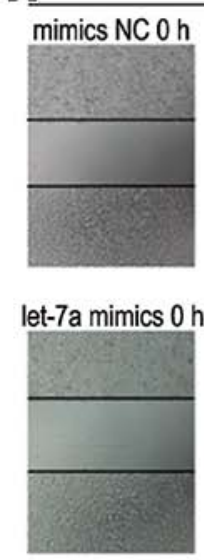

inhibitor $\mathrm{NCOh}$
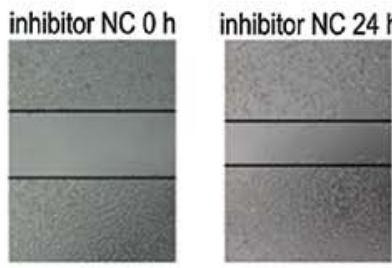

inhibitor NC $48 \mathrm{~h}$

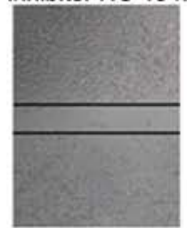

let-7a inhibitor $0 \mathrm{~h}$ let-7a inhibitor $24 \mathrm{~h}$ let-7a inhibitor $48 \mathrm{~h}$
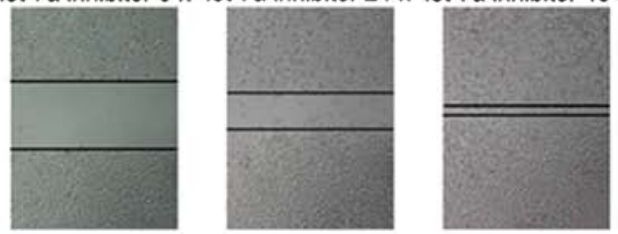

B

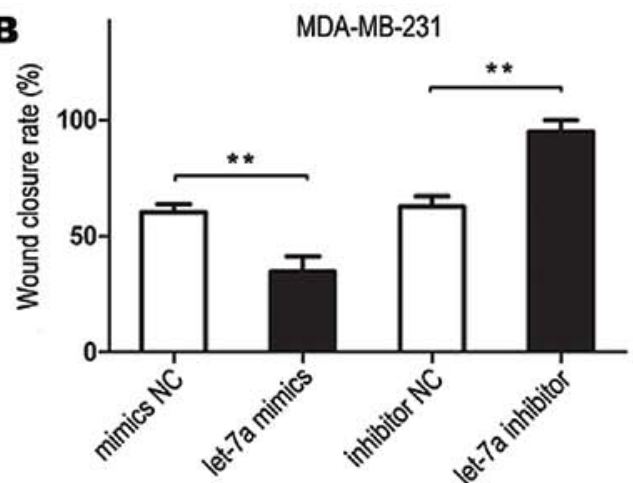

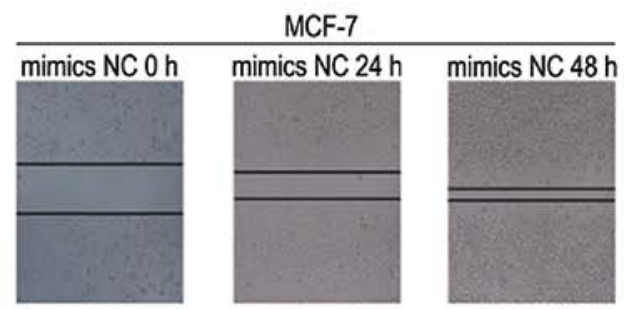

let-7a mimics $0 \mathrm{~h}$ let-7a mimics $24 \mathrm{~h}$ let-7a mimics $48 \mathrm{~h}$
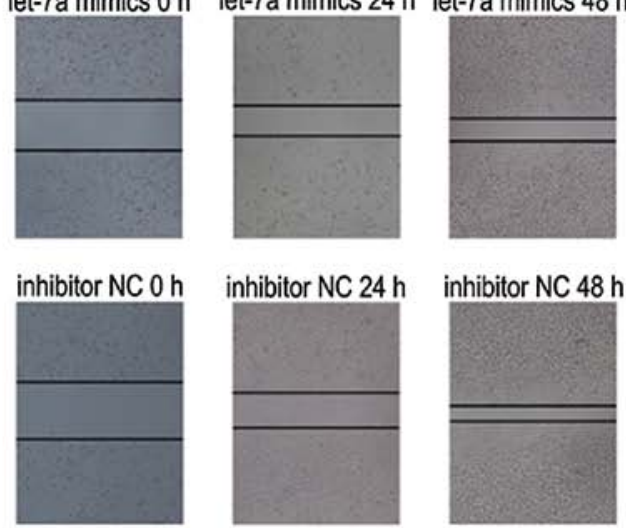

inhibitor NC $48 \mathrm{~h}$

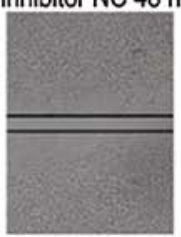

let-7a inhibitor $0 \mathrm{~h}$ let-7a inhibitor $24 \mathrm{~h}$ let-7a inhibitor $48 \mathrm{~h}$
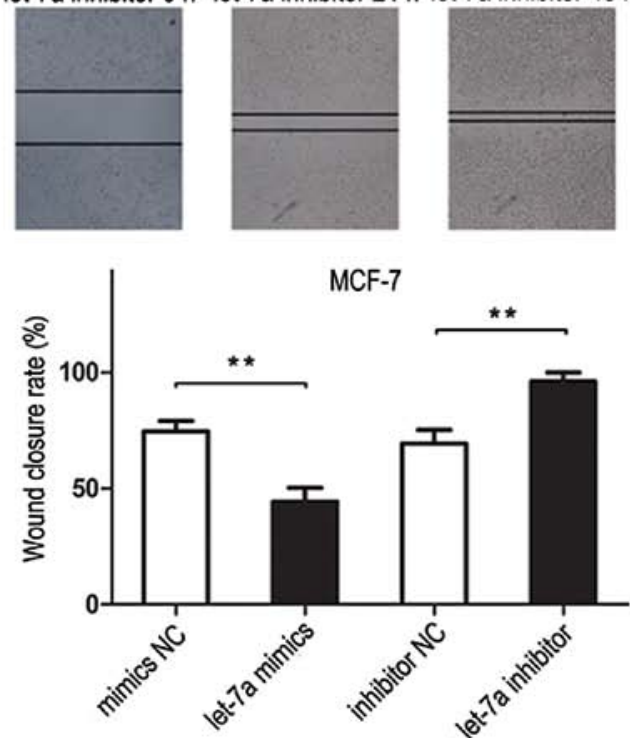

Figure 5. Let-7a inhibits cell migration. The migration of breast cancer cell lines (MDA-MB-231, MCF-7) transfected with let-7a mimics or let-7a inhibitor was examined by the cell scratch assay. Images were taken at 0,24 and $48 \mathrm{~h}$ after confluent cells had been scratched (A). The distance between the migrating front of the scratches was measured in three randomly selected microscopic fields for each condition and time point (x100). The degree of motility at $48 \mathrm{~h}$ after confluent cells had been scratched is expressed as percentage of wound closure which was calculated as follows: (the distance of cell migration at $48 \mathrm{~h} /$ the distance of scratch at $0 \mathrm{~h}$ ) $\times 100 \%$. The graph represents the mean of wound closure rates \pm SEM ( $\left.{ }^{* * *} \mathrm{P}<0.01\right)$. SEM, standard error of the mean (B).

(20 mM Tris- $\mathrm{HCl}$ (pH 7.4), $150 \mathrm{mM} \mathrm{NaCl}$, and 0.1\% Tween-20) at room temperature for $1 \mathrm{~h}$ and incubated with primary antibodies at $4^{\circ} \mathrm{C}$ overnight. The next day, the membranes were washed with TBST and then incubated with HRP-linked secondary antibodies (anti-rabbit IgG, diluted at 1:1000; Cell Signaling Technology). The protein bands were developed with chemiluminescence (ECL) reagents (Beyotime). The antibodies were anti-HMGA1 (diluted at 1:500; Abgent), antiGAPDH (diluted at 1:1000; Cell Signaling Technology).

Statistical analysis. For statistical analyses, mean values with standard deviation are shown in the graphs that were generated from several repeats of biological experiments. P-values were obtained from t-tests with paired or unpaired samples and $<0.05$ were considered significant.

\section{Results}

Let-7a is decreased in breast cancer tissues and breast cancer cells. We performed qRT-PCR to determine let-7a levels in breast cancer cells, 27 breast cancer tissues and adjacent normal breast tissues. As shown in Fig. 1, the expression levels of the let-7a were downregulated in cancer tissues compared to the adjacent normal tissues. We compared let-7a expression in breast cancer cell lines MDA-MB-231 and MCF-7 which was in the similar range of that in breast cancer tissues, thus we 
A

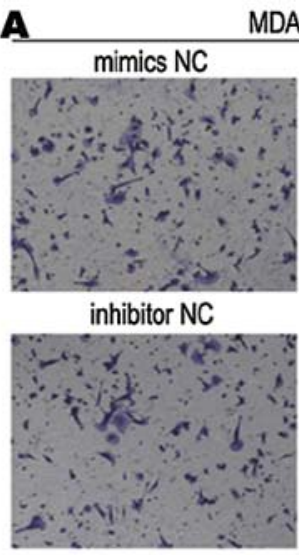

MDA-MB-231

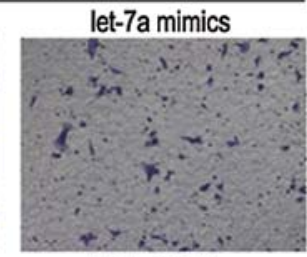

let-7a inhibitor

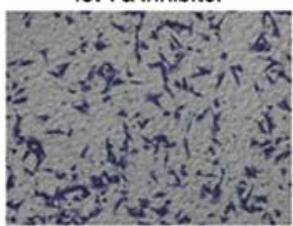

\section{B}

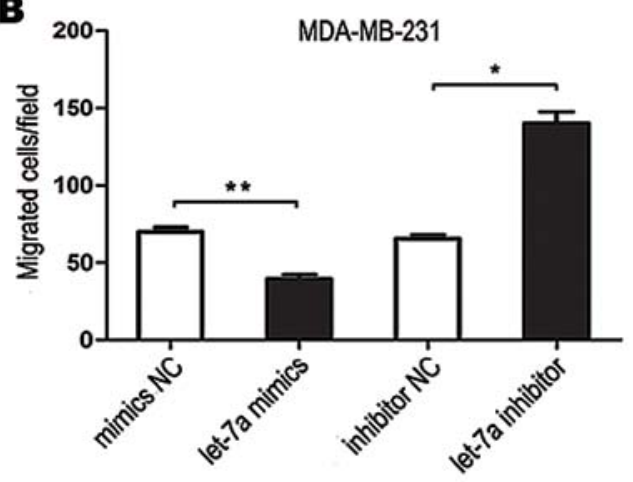

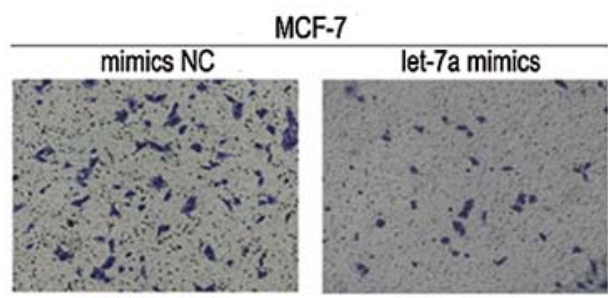

inhibitor NC

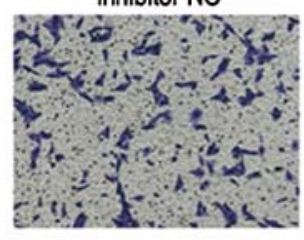

let-7a inhibitor
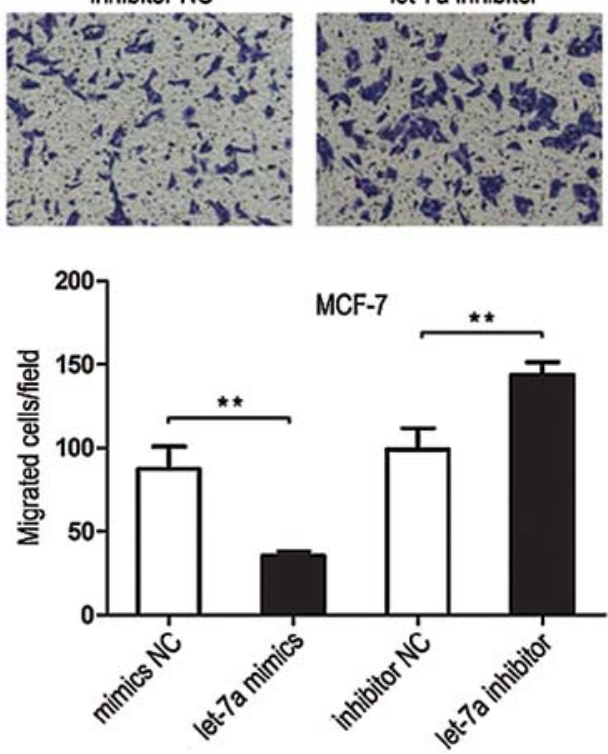

Figure 6. Let-7a inhibited cell invasion. Cell invasion was analyzed by Transwell chamber assay in breast cancer cells lines (MDA-MB-231, MCF-7) transfected with let-7a mimics or let-7a inhibitor. Representative images of crystal violet-stained migrated cells were captured after $14 \mathrm{~h}$ for MDA-MB-231 and $16 \mathrm{~h}$ for MCF-7 of the invasion using an inverted microscope with x100 magnification (A). Quantiication of the number of crystal violet-stained cells. Data represent the number of the migrated cells shown as means \pm SEM $\left({ }^{*} \mathrm{P}<0.05,{ }^{* *} \mathrm{P}<0.01\right)$. SEM, standard error of the mean $(\mathrm{B})$.

used these two breast cancer cell lines for further experiments in this study. To confirm the function of let-7a, we transfected let-7a mimics and inhibitor into breast cancer cell lines (MDA-MB-231 and MCF-7). At $6 \mathrm{~h}$ after transfection of let-7a mimics and inhibitor into breast cancer cells, the transfection efficiency were estimated by fluorescence microscopy and the let-7a expression level was verified by real-time PCR (Fig. 2). We found that let-7a mimics significantly increased let-7a RNA expression while let-7a inhibitor significantly decreased let-7a RNA expression in both breast cancer cell lines.

Let-7a inhibits breast cancer cell proliferation. Breast cancer cells were treated with let-7a mimics or mimics $\mathrm{NC}$ and let-7a inhibitor or inhibitor NC for 24, 48, $72 \mathrm{~h}$ and measured the absorbance at $490 \mathrm{~nm}$. Compared with the treatment with the mimics NC, cell proliferation was inhibited when cells were treated with let-7a mimics. Compared with the inhibitor NC treatment, cell proliferation was promoted when cells were treated with let-7a inhibitor (Fig. 3).

Let-7a decreases breast cancer cell colony formation. Colonies formed from let-7a mimic-transfected cells were significantly less than that of mimics NC transfected cells. The let-7a inhibitor transfected cells formed significantly more colonies than that of inhibitor NC transfected cells (Fig. 4). These data demonstrated that let-7a inhibited breast cancer cell colony formation.
Let-7a inhibits breast cancer cells migration. Cell scratch assay showed that cells transfected with let-7a mimics migrated slowly. The scratch in mimics NC treated cells was almost healed $48 \mathrm{~h}$ after the scratch had been made, but not in let-7a mimics treated cells. The cells transfected with let-7a inhibitor migrated more rapidly than cells transfected with inhibitor NC (Fig. 5). These data demonstrated that let-7a inhibited breast cancer cell migration.

Let-7a inhibited breast cancer cell invasion. Transwell invasion assays showed that the number of tumor cells invading out of the chamber after treatment with let-7a mimics was significantly less than that after treatment with mimics NC. The number of tumor cells invading from the chamber after treatment of let-7a inhibitor was significantly more than that after treatment with inhibitor NC, demonstrating that let-7a inhibited tumor cell invasion (Fig. 6).

HMGA1 is a target gene of let-7a. In silico analyses of potential let-7a targets (www.microrna.org and www.targetscan. org) indicated that the proteins of the high mobility group A1 (HMGA1) is a possible target of let-7a. HMGA1 mRNA has one potential complimentary binding site with let-7a within its 3' UTR (Fig. 7A). Based on these results, we performed qRT-PCR assays and western blot analysis to assess the impact of let-7a on HMGA1 expression. Although we did not find apparent effects on HMGA1 mRNA expression in the 
A 3'uugauauguUggaugauggagu 5' hsa-let-7a

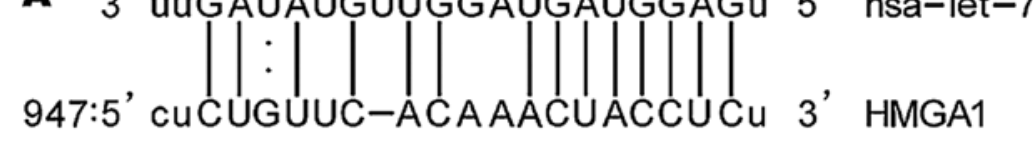
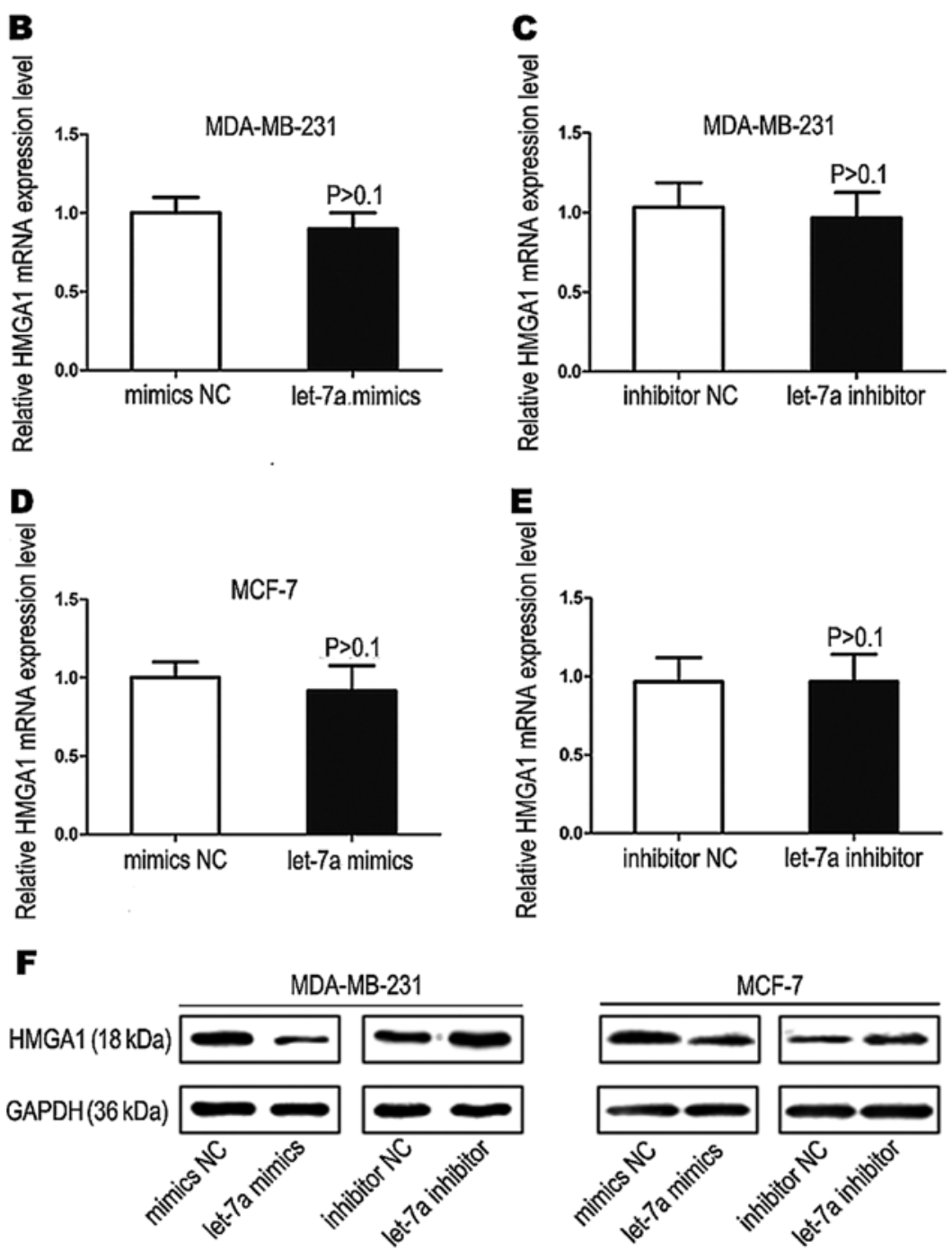

Figure 7. HMGA1 is a target of let-7a in breast cancer. Schematic diagram illustrated potential let-7a binding site of HMGA1 mRNA predicted in silico (A). HMGA1 mRNA expression in breast cancer cells lines (MDA-MB-231, MCF-7) at $48 \mathrm{~h}$ post-transfection of let-7a mimics or let-7a inhibitor was analyzed by qRT-PCR. The graph represents the relative expression levels of HMGA1 mRNA in cells transfected with let-7a mimics (B and D) or let-7a inhibitor (C and E) compared to their negative controls (mimics NC or inhibitor NC) shown as the mean of $2^{-\Delta \Delta C t}$ values \pm SEM. SEM, standard error of the mean. HMGA1 protein expression was analyzed by western blotting at $48 \mathrm{~h}$ post-transfection (F). GAPDH was used as an internal control.

breast cancer cells after treatment of let-7a mimics or mimics $\mathrm{NC}$ and let-7a inhibitor or inhibitor NC (Fig. 7B-E), western blot analysis showed that HMGA1 protein expression was significantly decreased or increased in let-7a mimics or let-7a inhibitor transfected cells (Fig. 7F). These data suggest that let-7a may target HMGA1 mRNA, and inhibits its translation into proteins.

\section{Discussion}

Breast cancer is the most common type of malignant tumor and its metastatic progression is a complex process (27-30). At present, surgery and chemotherapy are the primary treatments for breast cancer, but many patients under chemotherapy have early tumor recurrence and metastasis, which results in poor prognosis. Consequently, it is especially important to explore targeted treatment for breast cancer. Over the last decades, miRNA has become a hotspot for research. Previous studies suggest that dysregulation of miRNAs is a common event in breast cancer (31) and that they may thus act as key regulators of tumorigenesis of breast cancer. Based on these findings, it has been proposed that more effective targeted drugs for treatment of breast cancer may involve miRNAs.

Among human cancer-related miRNAs, the let-7 family has attracted significant attention because its family members are expressed aberrantly in many cancers, such as lung carcinoma, and colon carcinoma $(20,22)$. As a member of the let-7 miRNA family, let-7a has been reported to be expressed at lower than normal levels in a variety of cancer (32-34). However, the suppressive role of let-7a in tumorigenesis is still 
poorly understood. In this study, we examined the expression levels of let-7a in breast cancer cells (MDA-MB-231 and MCF-7), breast cancer tissues and corresponding adjacent normal tissues. We found that the expression of let-7a was significantly lower in breast cancer cells and breast cancer tissues than corresponding adjacent normal tissues, which suggested that downregulation of let-7a was associated with the development of breast cancer. Thus, we hypothesized that let-7a may function as a tumor suppressor. To prove the role of let-7a in breast cancer, we transfected let-7a mimics or let-7a inhibitor into breast cancer cells to induce overexpression or low expression of let-7a. Exogenous overexpression of let-7a significantly inhibited the cell growth as indicated by MTT and colony formation assays whereas low expression of let-7a significantly promote cell growth. Moreover, cell migration and invasion were also significantly decreased or increased by overexpression or low expression of let-7a in breast cancer cells as shown by wound healing and Transwell assays. Recent evidence indicated that let-7a plays a role in the progression of human tumors such as renal cell carcinoma, gastric carcinoma and hepatocellular carcinoma (35-37). In addition, it has been shown that let-7a is downregulated in Burkitt's lymphoma and acted as an anticancer miRNA repressing C-MYC expression at the translational level (38). These previous studies are consistent with our current data, suggesting that let-7a plays a role as a tumor suppressor in regulation of breast cancer progression.

In this study, we first predicted by online biological software that HMGA1 is a potential target gene of let-7a. HMGA family members have previously been reported to be involved in breast carcinogenesis (39). They are non-histone and DNA-binding proteins, which are often referred to as architectural transcription factors. They contain basic A-T hook domains which mediate binding to the minor groove of AT-rich regions of chromosomal DNA. Upon binding to DNA, HMGA proteins regulate gene expression by forming the transcriptional complex through protein-protein and protein-DNA interactions (40-42). The HMGA family includes the products of the HMGA1 and HMGA2 genes. HMGA1 has been found to be abnormally expressed in several types of malignant tumors, including breast (43-45), ovarian (46), leukemia (47), colon (48), pancreatic (49), thyroid (50), lung (51), prostate (52), endometrial (53), and head and neck malignant tumor (54).

Next, we tested whether HMGA1 is a target of let-7a by qRT-PCR and western blotting. Noteworthy, we found that the mRNA expression of HMGA1 did not alter in let-7a mimics or let-7a inhibitor transfected breast cancer cells, but protein expression was significantly decreased or increased in let-7a mimics or let-7a inhibitor transfected cells. Previous studies indicated that one miRNA might have multiple mRNA targets and that one mRNA might be targeted by multiple miRNAs. When a miRNA is perfectly complementary to its target, it can specifically degrade the target mRNA (55). However, if it is not perfectly complementary to its target, the miRNA will inhibit mRNA translation (56). Most miRNAs are involved in the regulation of the expression of target genes through the two pathways discussed above (57). Therefore, the result indicates that let-7a is not perfectly complementary to its target. In other words, let-7a regulates HMGA1 only at protein level, but not at the genetic level. The result also confirmed the prediction from bioinformatics.
Collectively, these data strongly suggested that let-7a might act as a tumor suppressor in breast cancer by targeting HMGA1. The upregulation of let-7a targeting HMGA1 shows promise as new strategy to treat breast cancer.

\section{Acknowledgements}

This study was supported by the foundation of the Jiangsu University for senior talented man (Grant no. 11JDG0089), the innovation project of Cultivating Graduate of Jiangsu Province (Grant no. CXLX13_689) and the Science Foundation of Kunshan (Grant no. KS1331).

\section{References}

1. Gonzalez-Angulo AM, Morales-Vasquez F and Hortobagyi GN: Overview of resistance to systemic therapy in patients with breast cancer. Adv Exp Med Biol 608: 1-22, 2007.

2. Lv YG, Yu F, Yao Q, Chen JH and Wang L: The role of survivin in diagnosis, prognosis and treatment of breast cancer. $\mathrm{J}$ Thorac Dis 2: 100-110, 2010.

3. Ambros V: microRNAs: Tiny regulators with great potential. Cell 107: 823-826, 2001.

4. de Moor CH, Meijer H and Lissenden S: Mechanisms of translational control by the $3^{\prime}$ UTR in development and differentiation. Semin Cell Dev Biol 16: 49-58, 2005.

5. Lee RC, Feinbaum RL and Ambros V: The C.elegans heterochronic gene lin-4 encodes small RNAs with antisense complementarity to lin-14. Cell 75: 843-854, 1993.

6. Iorio MV, Ferracin M, Liu CG, Veronese A, Spizzo R, Sabbioni S, Magri E, Pedriali M, Fabbri M, Campiglio M, et al: MicroRNA gene expression deregulation in human breast cancer. Cancer Res 65: 7065-7070, 2005.

7. Croce CM: Causes and consequences of microRNA dysregulation in cancer. Nat Rev Genet 10: 704-714, 2009.

8. Esquela-Kerscher A and Slack FJ: Oncomirs - microRNAs with a role in cancer. Nat Rev Cancer 6: 259-269, 2006.

9. Blenkiron C, Goldstein LD, Thorne NP, Spiteri I, Chin SF, Dunning MJ, Barbosa-Morais NL, Teschendorff AE, Green AR, Ellis IO, et al: MicroRNA expression profiling of human breast cancer identifies new markers of tumor subtype. Genome Biol 8: $\mathrm{R} 214,2007$.

10. Silveri L, Tilly G, Vilotte JL and Le Provost F: MicroRNA involvement in mammary gland development and breast cancer. Reprod Nutr Dev 46: 549-556, 2006.

11. Hui AB, Shi W, Boutros PC, Miller N, Pintilie M, Fyles T, McCready D, Wong D, Gerster K, Waldron L, et al: Robust global micro-RNA profiling with formalin-fixed paraffin-embedded breast cancer tissues. Lab Invest 89: 597-606, 2009.

12. Chen X, Guo X, Zhang H, Xiang Y, Chen J, Yin Y, Cai X, Wan K, Wang G, Ba Y, et al: Role of miR-143 targeting KRAS in colorectal tumorigenesis. Oncogene 28: 1385-1392, 2009.

13. Nicoloso MS, Spizzo R, Shimizu M, Rossi S and Calin GA: MicroRNAs - the micro steering wheel of tumour metastases. Nat Rev Cancer 9: 293-302, 2009.

14. Hui AB, Lenarduzzi M, Krushel T, Waldron L, Pintilie M, Shi W, Perez-Ordonez B, Jurisica I, O'Sullivan B, Waldron J, et al: Comprehensive microRNA profiling for head and neck squamous cell carcinomas. Clin Cancer Res 16: 1129-1139, 2010.

15. Gramantieri L, Ferracin M, Fornari F, Veronese A, Sabbioni S, Liu CG, Calin GA, Giovannini C, Ferrazzi E, Grazi GL, et al: Cyclin G1 is a target of miR-122a, a microRNA frequently downregulated in human hepatocellular carcinoma. Cancer Res 67: 6092-6099, 2007.

16. Hiyoshi Y, Kamohara H, Karashima R, Sato N, Imamura Y, Nagai Y, Yoshida N, Toyama E, Hayashi N, Watanabe M, et al: MicroRNA-21 regulates the proliferation and invasion in esophageal squamous cell carcinoma. Clin Cancer Res 15: 1915-1922, 2009.

17. Ma L, Teruya-Feldstein J and Weinberg RA: Tumour invasion and metastasis initiated by microRNA-10b in breast cancer. Nature 449: 682-688, 2007.

18. Ma J, Dong C and Ji C: MicroRNA and drug resistance. Cancer Gene Ther 17: 523-531, 2010. 
19. Zhang L, Huang J, Yang N, Greshock J, Megraw MS, Giannakakis A,Liang S, Naylor TL, Barchetti A, Ward MR, et al: microRNAs exhibit high frequency genomic alterations in human cancer. Proc Natl Acad Sci USA 103: 9136-9141, 2006.

20. Takamizawa J, Konishi H, Yanagisawa K, Tomida S, Osada H, Endoh H, Harano T, Yatabe Y, Nagino M, Nimura Y, et al: Reduced expression of the let-7 microRNAs in human lung cancers in association with shortened postoperative survival. Cancer Res 64: 3753-3756, 2004

21. Reinhart BJ, Slack FJ, Basson M, Pasquinelli AE, Bettinger JC, Rougvie AE, Horvitz HR and Ruvkun G: The 21-nucleotide let-7 RNA regulates developmental timing in Caenorhabditis elegans. Nature 403: 901-906, 2000.

22. Akao Y, Nakagawa Y and Naoe T: let-7 microRNA functions as a potential growth suppressor in human colon cancer cells. Biol Pharm Bull 29: 903-906, 2006.

23. Park SM, Shell S, Radjabi AR, Schickel R, Feig C, Boyerinas B, Dinulescu DM, Lengyel E and Peter ME: Let-7 prevents early cancer progression by suppressing expression of the embryonic gene HMGA2. Cell Cycle 6: 2585-2590, 2007.

24. Wong TS, Man OY, Tsang CM, Tsao SW, Tsang RK, Chan JY, Ho WK, Wei WI and To VS: MicroRNA let-7 suppresses nasopharyngeal carcinoma cells proliferation through downregulating c-Myc expression. J Cancer Res Clin Oncol 137: 415-422, 2011.

25. He XY, Chen JX, Zhang Z, Li CL, Peng QL and Peng HM: The let-7a microRNA protects from growth of lung carcinoma by suppression of K-Ras and c-Myc in nude mice. J Cancer Res Clin Oncol 136: 1023-1028, 2010.

26. Long XB, Sun GB, Hu S, Liang GT, Wang N, Zhang XH, Cao PP, Zhen HT, Cui YH and Liu Z: Let-7a microRNA functions as a potential tumor suppressor in human laryngeal cancer. Oncol Rep 22: 1189-1195, 2009.

27. Chiang AC and Massagué J: Molecular basis of metastasis. N Engl J Med 359: 2814-2823, 2008.

28. Talmadge JE and Fidler IJ: AACR centennial series: the biology of cancer metastasis: historical perspective. Cancer Res 70 : $5649-5669,2010$

29. Hanahan D and Weinberg RA: Hallmarks of cancer: The next generation. Cell 144: 646-674, 2011

30. Valastyan S and Weinberg RA: MicroRNAs: Crucial multitasking components in the complex circuitry of tumor metastasis. Cell Cycle 8: 3506-3512, 2009.

31. Li LZ, Zhang CZ, Liu LL, Yi C, Lu SX, Zhou X, Zhang ZJ, Peng YH, Yang YZ and Yun JP: miR-720 inhibits tumor invasion and migration in breast cancer by targeting TWIST1 Carcinogenesis 35: 469-478, 2014.

32. Johnson CD, Esquela-Kerscher A, Stefani G, Byrom M, Kelnar K, Ovcharenko D, Wilson M, Wang X, Shelton J, Shingara J, et al: The let-7 microRNA represses cell proliferation pathways in human cells. Cancer Res 67: 7713-7722, 2007.

33. Meng F, Henson R, Wehbe-Janek H, Smith H, Ueno Y and Patel T: The microRNA let-7a modulates interleukin-6-dependent STAT-3 survival signaling in malignant human cholangiocytes. J Biol Chem 282: 8256-8264, 2007

34. Mayr C, Hemann MT and Bartel DP: Disrupting the pairing between let-7 and Hmga2 enhances oncogenic transformation. Science 315: 1576-1579, 2007.

35. Liu Y, Yin B, Zhang C, Zhou L and Fan J: Hsa-let-7a functions as a tumor suppressor in renal cell carcinoma cell lines by targeting c-myc. Biochem Biophys Res Commun 417: 371-375, 2012.

36. Yang Q, Jie Z, Cao H, Greenlee AR, Yang C, Zou F and Jiang Y: Low-level expression of let-7a in gastric cancer and its involvement in tumorigenesis by targeting RAB40C. Carcinogenesis 32 : 713-722, 2011

37. Wang Y, Lu Y, Toh ST, Sung WK, Tan P, Chow P, Chung AY, Jooi LL and Lee CG: Lethal-7 is down-regulated by the hepatitis B virus x protein and targets signal transducer and activator of transcription 3. J Hepatol 53: 57-66, 2010.

38. Sampson VB, Rong NH, Han J, Yang Q, Aris V, Soteropoulos P, Petrelli NJ, Dunn SP and Krueger LJ: MicroRNA let-7a downregulates MYC and reverts MYC-induced growth in Burkitt lymphoma cells. Cancer Res 67: 9762-9770, 2007.

39. Peluso S and Chiappetta G: High-mobility group A (HMGA) proteins and breast cancer. Breast Care (Basel) 5: 81-85, 2010.
40. Reeves R and Beckerbauer L: HMGI/Y proteins: Flexible regulators of transcription and chromatin structure. Biochim Biophys Acta 1519: 13-29, 2001.

41. Fedele M and Fusco A: HMGA and cancer. Biochim Biophys Acta 1799: 48-54, 2010

42. Resar LM: The high mobility group A1 gene: Transforming inflammatory signals into cancer? Cancer Res 70: 436-439, 2010.

43. Dolde CE, Mukherjee M, Cho C and Resar LM: HMG-I/Y in human breast cancer cell lines. Breast Cancer Res Treat 71: 181-191, 2002.

44. Chiappetta G, Ottaiano A, Vuttariello E, Monaco M, Galdiero F, Gallipoli A, Pilotti S, Jodice G, Siranoush M, Colombo M, et al: HMGA1 protein expression in familial breast carcinoma patients. Eur J Cancer 46: 332-339, 2010.

45. Flohr AM, Rogalla P, Bonk U, Puettmann B, Buerger H, Gohla G, Packeisen J, Wosniok W, Loeschke S and Bullerdiek J: High mobility group protein HMGA1 expression in breast cancer reveals a positive correlation with tumour grade. Histol Histopathol 18: 999-1004, 2003.

46. Masciullo V, Baldassarre G, Pentimalli F, Berlingieri MT, Boccia A, Chiappetta G, Palazzo J, Manfioletti G, Giancotti V, Viglietto G, et al: HMGA1 protein over-expression is a frequent feature of epithelial ovarian carcinomas. Carcinogenesis 24: 1191-1198, 2003

47. Xu Y, Sumter TF, Bhattacharya R, Tesfaye A, Fuchs EJ, Wood LJ, Huso DL and Resar LM: The HMG-I oncogene causes highly penetrant, aggressive lymphoid malignancy in transgenic mice and is overexpressed in human leukemia. Cancer Res 64 : 3371-3375, 2004

48. Chiappetta G, Manfioletti G, Pentimalli F, Abe N, Di Bonito M, Vento MT, Giuliano A, Fedele M, Viglietto G, Santoro M, et al: High mobility group HMGI(Y) protein expression in human colorectal hyperplastic and neoplastic diseases. Int J Cancer 91: 147-151, 2001.

49. Abe N, Watanabe T, Masaki T, Mori T, Sugiyama M, Uchimura H, Fujioka Y, Chiappetta G, Fusco A and Atomi Y: Pancreatic duct cell carcinomas express high levels of high mobility group I(Y) proteins. Cancer Res 60: 3117-3122, 2000.

50. Chiappetta G, Tallini G, De Biasio MC, Manfioletti G, Martinez-Tello FJ, Pentimalli F, de Nigris F, Mastro A, Botti G, Fedele M, et al: Detection of high mobility group I HMGI(Y) protein in the diagnosis of thyroid tumors: HMGI(Y) expression represents a potential diagnostic indicator of carcinoma. Cancer Res 58: 4193-4198, 1998.

51. Hillion J, Wood LJ, Mukherjee M, Bhattacharya R, Di Cello F, Kowalski J, Elbahloul O, Segal J, Poirier J, Rudin CM, et al: Upregulation of MMP-2 by HMGA1 promotes transformation in undifferentiated, large-cell lung cancer. Mol Cancer Res 7: 1803-1812, 2009

52. Tamimi Y, van der Poel HG, Denyn MM, Umbas R, Karthaus HF, Debruyne FM and Schalken JA: Increased expression of high mobility group protein $\mathrm{I}(\mathrm{Y})$ in high grade prostatic cancer determined by in situ hybridization. Cancer Res 53: 5512-5516, 1993.

53. Tesfaye A, Di Cello F, Hillion J, Ronnett BM, Elbahloul O, Ashfaq R, Dhara S, Prochownik E, Tworkoski K, Reeves R, et al: The high-mobility group A1 gene up-regulates cyclooxygenase 2 expression in uterine tumorigenesis. Cancer Res 67: 3998-4004, 2007.

54. Rho YS, Lim YC, Park IS, Kim JH, Ahn HY, Cho SJ and Shin HS: High mobility group HMGI(Y) protein expression in head and neck squamous cell carcinoma. Acta Otolaryngol 127: 76-81, 2007.

55. Hornstein E, Mansfield JH, Yekta S, Hu JK, Harfe BD, McManus MT, Baskerville S, Bartel DP and Tabin CJ: The microRNA miR-196 acts upstream of Hoxb8 and Shh in limb development. Nature 438: 671-674, 2005.

56. Wightman B, Ha I and Ruvkun G: Posttranscriptional regulation of the heterochronic gene lin-14 by lin- 4 mediates temporal pattern formation in C. elegans. Cell 75: 855-862, 1993

57. Bartel DP: MicroRNAs: Genomics, biogenesis, mechanism, and function. Cell 116: 281-297, 2004. 